\title{
The Comparison of the Analgesic and Anti-Inflammatory Effect of Two NSAIDs in Patients Undergoing Third Molar Surgery Using C - Reactive Protein Estimation
}

\author{
K. Raja Harsha1, Titus K. Thomas ${ }^{2}$ \\ 1, 2 Department of Oral and Maxillofacial Surgery, Meenakshi Ammal Dental College and Hospital, \\ Chennai, Tamilnadu, India.
}

\section{ABSTRACT}

\section{BACKGROUND}

Surgical removal of the lower impacted third molar is the most classic procedure performed in oral surgery. This procedure is often linked with hard and soft tissue manipulation leading to activation of acute-phase inflammatory response. This has led to the development of serum inflammatory biomarkers which has given the advantage of reducing the prolonged use of prophylactic antibiotics and an analgesic. The purpose of this study was to determine the analgesic and antiinflammatory effects of two NSAIDs in patients undergoing third molar surgery and assess the serum CRP levels preoperatively and postoperatively.

\section{METHODS}

Our study was carried out on twenty (20) healthy volunteering young adults who reported to the Department of Oral and Maxillofacial Surgery, Meenakshi Ammal Dental College \& Hospital, Chennai, for the surgical removal of impacted mandibular third molars. Patients were enrolled in two groups. Each group was subjected to the withdrawal of a venous blood sample of $2 \mathrm{ml}$ preoperatively, immediately $1 \mathrm{hr}$ after the surgery and on the third postoperative day. A turbidimetric test was done for CRP level on all these samples and the results were analyzed.

\section{RESULTS}

An investigation was performed to find the association of gender, age, difficulty index, duration of surgery and pain scores by using a biochemical marker - C reactive protein. The ibuprofen group showed increased postoperative $72 \mathrm{hr}$ CRP levels and diclofenac group showed decreased postoperative $72 \mathrm{hr}$ CRP levels in comparison to initially measured preoperative CRP levels regardless of an increase or decrease in the duration of the surgery.

\section{CONCLUSIONS}

Thus, it can be concluded that a non-steroidal anti-inflammatory drug like diclofenac is a better analgesic and anti-inflammatory drug than ibuprofen in controlling the pain perception and inflammation responses based on inflammatory biomarker-C-reactive protein levels. An inflammatory biomarker like CRP is a reliable and potent indicator of various inflammatory responses.
Corresponding Author:

Dr. K. Raja Harsha, AWHO Ved Vihar, Block-91, Subash Nagar, Secunderabad-500015,

Telangana, India.

E-mail: harsha.kalangi@gmail.com

DOI: $10.14260 /$ jemds/2022/77

How to Cite This Article:

Harsha KR, Thomas TK. The comparison of the analgesic and anti-inflammatory effect of two NSAIDs in patients undergoing third molar surgery using $C$-reactive protein estimation. J Evolution Med Dent Sci 2022;11(03):401-405, 10.14260/jemds/2022/77 DOI:

Submission 26-12-2020,

Peer Review 05-02-2022,

Acceptance 11-02-2022,

Published 14-02-2022.

Copyright (C) 2022 K. Raja Harsha et al. This is an open access article distributed under Creative Commons Attribution License [Attribution 4.0 International (CC $B Y 4.0)]$

\section{KEY WORDS}

NSAIDS, CRP, Molar, Analgesics. 


\section{BACKGROUND}

The surgical removal of the lower impacted third molar is the most classic procedure performed in oral surgery. ${ }^{1,2}$ The procedure is often linked with hard and soft tissue manipulation leading to activation of the acute-phase inflammatory response which progresses with some common postoperative sequelae, pain, swelling, trismus, and the cytokines playing the major role. The pharmacological nature of non-steroidal anti-inflammatory drugs is antiinflammatory, analgesic, and antipyretic.3,4

Human $\mathrm{C}$ reactive protein is highly sensitive and a powerful inflammatory marker belonging to the "Pentraxin family" discovered in Oswald Avery's laboratory by Tillet and Francis (1930) in patients suffering from pneumonia infection, an etiological derivative of "Streptococcus pneumoniae" bacteria.5,6,7 CRP begins to become measurable within $4-5 \mathrm{hrs}$ after a single inflammatory stimulus and continues to elevate from $24-48 \mathrm{hrs}$ and decreases after 48 72 hrs and back to original levels. ${ }^{8}$ Normally in a healthy youngster, the concentration of C-reactive protein is $0.1-0.5$ $\mathrm{ug} / \mathrm{ml}$.

\section{Objectives}

1. To assess the serum CRP levels preoperatively and postoperatively following surgical removal of an impacted third molar.

2. To evaluate the postoperative changes in serum CRP levels of two NSAIDs.

3. To assess and compare the analgesic and antiinflammatory effects of "oral diclofenac and oral ibuprofen in controlling the postoperative pain and postoperative inflammatory response after completion of third molar extraction.

\section{METHODS}

This study is a parallel-group designed randomized clinical trial. In this the volunteering participants were randomized to one or more test drug study arms and each study arm was allocated a specific treatment intervention. After randomization, the participants stayed in their respective assigned treatment arms until the completion of the study. The steps involved were inclusion criteria, selection after the consent, randomization and 7 days follow up. The total number of participants was determined based on a twotailed hypothesis and non-central parametric statistics using SPSS software version 16 (SPSS Inc., Chicago, Illinois, USA).

The study was carried out on twenty healthy volunteering young adults, compiling to the Class I classification of American Society of Anaesthesiologists, who reported to the Department of Oral and Maxillofacial Surgery, Meenakshi Ammal Dental College \& Hospital, Chennai, for the surgical removal of impacted mandibular third molars. The institutional review board with ethical clearance was taken before the study initiation.

All the volunteering patients who satisfied the inclusion criteria underwent a full medical history, dental history, oral examination and radiographic analysis. An informed written consent was obtained from all volunteers after the study protocols were explained to each patient by the $3^{\text {rd }}$ year postgraduates. The participants were subjected to the withdrawal of three $2 \mathrm{ml}$ blood samples for the serum analysis at three different stages that is before surgery, immediate 1-hour post-surgery and on the third day post-op follow up.

The duration of surgery in minutes was recorded from the initial incision time to the last suture placed. Based on the duration of surgery, the procedures were classified as surgery within $30 \mathrm{~min}$ and surgery above $30 \mathrm{~min}$. All the patients were given written postoperative instructions and standard antibiotic therapy was given (Amoxicillin $500 \mathrm{mg}$ TID for 5 days and metrogyl 400 mg TID for 3 days) whereas the standardized study medications that is ibuprofen $400 \mathrm{mg}$ tablet and voveran $50 \mathrm{mg}$ tablet were randomly selected for each patient as they were enrolled into two groups (Ibuprofen group and diclofenac group) and were prescribed three times daily for 5 days.

All the blood samples collected were processed in the centrifuge at $3000 \mathrm{rpm}$ for $2 \mathrm{~min}$. The collected serum sample was transferred into Eppendorf tubes which were then stored at $4^{\circ} \mathrm{C}$ refrigeration. After receiving all serum samples were mixed with the CRP turbidimetric reagent. The mixed samples were carefully transferred into a Coralab 3000 biochemical analyzer for evaluating the CRP levels. During the follow-up period, the visual analogue scale scores were analyzed and recorded for both the groups on postoperative $3^{\text {rd }}, 4^{\text {th }}$ and $5^{\text {th }}$ days.

\section{Study Duration}

March 2016 - Dec. 2017

\section{Inclusion Criteria}

1. Healthy young adults of both genders with an age range of 18 to 35 years.

2. Patient's volunteering for withdrawal of three $2 \mathrm{ml}$ venous blood samples for the analysis of serum $\mathrm{C}$ reactive protein concentration levels.

3. Symptomatic unilateral impacted mandibular 3 rd molar with a difficulty degree range of (5-6).

\section{Exclusion Criteria}

1. History of alcoholism and smoking.

2. History of periapical and periradicular radiolucency.

3. History of periodontitis (radiographic diagnosis of vertical bone defects or bone resorption equal to $20 \%$ of the root length)

4. History of systemic inflammatory conditions.

5. History of allergy to study medication.

6. History of premedication within $30 \mathrm{~d}$ before the study inclusion

7. History of liver disorders.

8. History of gastrointestinal disorders.

9. History of systemic infectious conditions.

10. Pregnancy or lactating mothers.

11. Females using contraceptive methods 


\section{Statistical Analysis}

The statistical data acquired were analyzed using SPSS version 16 (SPSS Inc., Chicago, Illinois, USA). All the parameters were assessed using t-test and Pearson correlation. The t-test is a type of statistical test that is used to compare the mean of two groups. Pearson correlation is a method to correlate a possible two-way linear association between two continuous variables. A P-value of less than 0.05 was considered significant.

\section{Clinical Variables/Duration of Surgery \\ Ibuprofen Group}

In the ibuprofen group, $60 \%$ of cases within 30 mins time duration had a mean value of (6.6) scores and $40 \%$ of cases above 30 mins time duration had a mean value of (7.7) scores The duration of surgery in comparison with $5^{\text {th }}$ day VAS scores showed a statistical significance $(0.011)$.

\section{Diclofenac Group}

In the diclofenac group, $30 \%$ of cases within 30 mins time duration had a mean value of (1.0) and $70 \%$ of cases above 30 mins time duration had a mean value of (2.1).

The duration of surgery in comparison with $5^{\text {th }}$ day VAS scores showed a statistical significance (0.024)

\section{Visual Analogue Scale (VAS)}

Ibuprofen Group

In the paired comparison among $3^{\text {rd }}$, $4^{\text {th }}$ and $5^{\text {th }}$ day VAS scores, there was a statistical significance as shown in (Table I).

The Pearson correlation showed no statistical significance between age, gender, difficulty index, CRP values and time of intervention.

\begin{tabular}{|c|c|c|}
\hline Sl. No. & Parameters & Significance \\
\hline 1 & $\begin{array}{c}\text { VAS } 3^{\text {rd day }} \\
\text { Vs } \\
\text { VAS } 5^{\text {th }} \text { day } \\
\end{array}$ & $\begin{array}{l}.004 \\
.032\end{array}$ \\
\hline 2 & $\begin{array}{c}\text { VAS } 4^{\text {th }} \text { day } \\
\text { Vs } \\
\text { VAS } 5^{\text {th }} \text { day }\end{array}$ & $\begin{array}{l}.004 \\
.000\end{array}$ \\
\hline 3 & $\begin{array}{c}\text { VAS } 3^{\text {rd d day }} \\
\text { Vs } \\
\text { VAS } 4^{\text {th }} \text { day }\end{array}$ & $\begin{array}{l}.000 \\
.032 \\
\end{array}$ \\
\hline \multicolumn{3}{|c|}{ Table 1. Pair-Comparison Statistics } \\
\hline
\end{tabular}

\section{Diclofenac Group}

In the paired comparison among $3^{\text {rd }}, 4^{\text {th }}$ and $5^{\text {th }}$-day VAS scores, there was a statistical significance as shown in Table II.

The Pearson correlation showed no statistical significance between age, gender, difficulty index, CRP values and time of intervention.

\begin{tabular}{|c|c|c|}
\hline Sl. No. & Parameters & Significance \\
\hline 1 & $\begin{array}{c}\text { VAS } 3^{\text {rd day }} \\
\text { Vs } \\
\text { VAS } 5^{\text {th }} \text { day }\end{array}$ & $\begin{array}{l}.157 \\
.019\end{array}$ \\
\hline 2 & $\begin{array}{l}\text { VAS } 4^{\text {th }} \text { day } \\
\text { Vs } \\
\text { VAS } 5^{\text {th }} \text { day }\end{array}$ & $\begin{array}{l}.157 \\
.012\end{array}$ \\
\hline 3 & $\begin{array}{c}\text { VAS } 3^{\text {rd }} \text { day } \\
\text { Vs } \\
\text { VAS } 4^{\text {th }} \text { day }\end{array}$ & $\begin{array}{l}.012 \\
.019\end{array}$ \\
\hline \multicolumn{3}{|c|}{ Table II. Diclofenac Group } \\
\hline
\end{tabular}

\section{Laboratory Variables \\ CRP Values \\ Ibuprofen Group}

In the paired comparison groups, there was no statistical significance observed. The Pearson correlation showed no statistical significance between age, duration of surgery, CRP values and the $3^{\text {rd }}, 4^{\text {th }}$ and $5^{\text {th }}$ VAS scores.

\section{Diclofenac Group}

In the paired comparison groups, there was no statistical significance observed. The Pearson correlation showed no statistical significance between age, duration of surgery, CRP values and the $3^{\text {rd, }} 4^{\text {th }}$ and $5^{\text {th }}$ VAS scores.

\section{RESULTS}

\section{Duration of Surgery}

In the ibuprofen group, 6 cases within $30 \mathrm{~min}$ had a mean time of 33.4 mins and 4 cases above 30 min with a mean time of 51.2 mins. In the diclofenac group, 3 cases within $30 \mathrm{~min}$ had a mean time of 25 mins and 7 cases above $30 \mathrm{~min}$ had a mean time of 45 mins.

\section{Visual Analogue Scale Scores (VAS)}

The VAS scores were analyzed in both the groups on postoperative $3^{\text {rd }}, 4^{\text {th }}$ and $5^{\text {th }}$ days. In the ibuprofen group, VAS $3^{\text {rd }}$ day showed a mean value of (8.6) score. The VAS $4^{\text {th }}$ day showed a mean value (7.9) score and VAS $5^{\text {th }}$ day had a mean value of (7.1) score. In the diclofenac group, VAS $3^{\text {rd }}$ day showed a mean value of (3.6) score, VAS $4^{\text {th }}$ day showed a mean value (3.1) and VAS $5^{\text {th }}$ day had a mean value of (1.8) score.
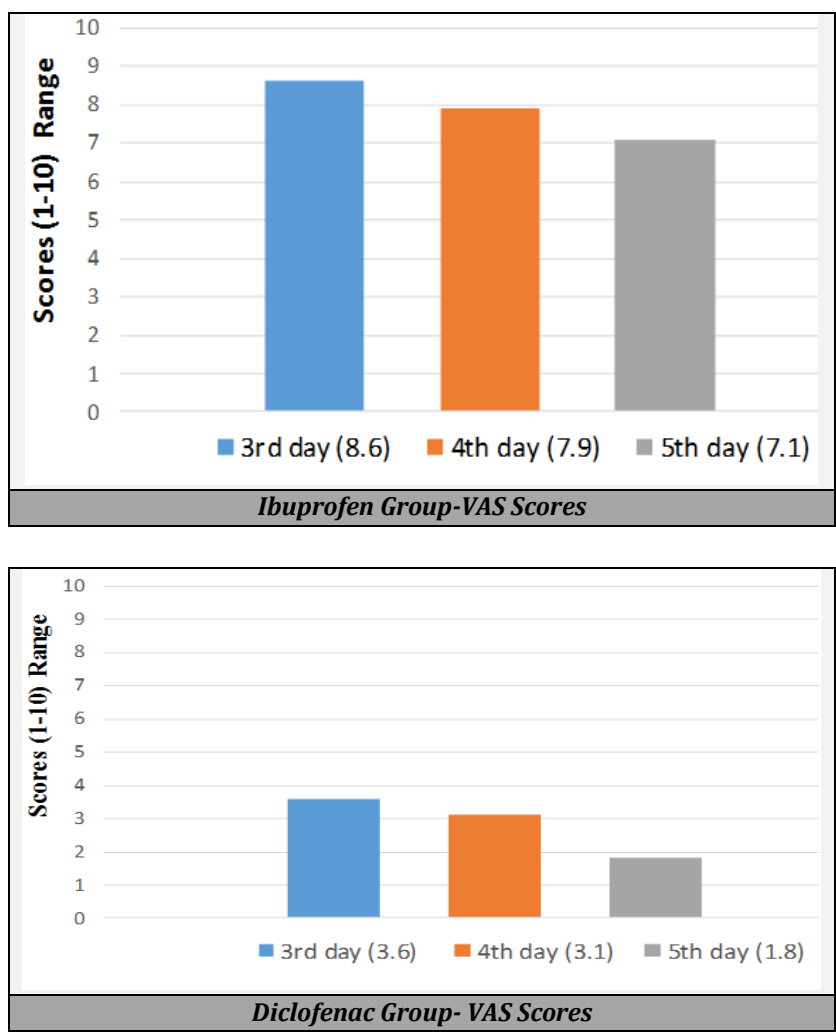


\section{Laboratory Variables}

\section{Preoperative CRP Levels}

The ibuprofen group showed a mean value of (4.6) $\mathrm{mg} / \mathrm{dl}$ and the diclofenac group had a mean value of (4.3) $\mathrm{mg} / \mathrm{dl}$.

Immediate Postoperative CRP Levels

The ibuprofen group showed a mean value of $(4.42) \mathrm{mg} / \mathrm{dl}$ and the diclofenac group showed a mean value of (5.03) $\mathrm{mg} / \mathrm{d}$.

\section{Hours Postoperative CRP Levels}

The ibuprofen group showed a mean value of (4.82) $\mathrm{mg} / \mathrm{dl}$ and the diclofenac group showed a mean value of (4.51) $\mathrm{mg} / \mathrm{dl}$.
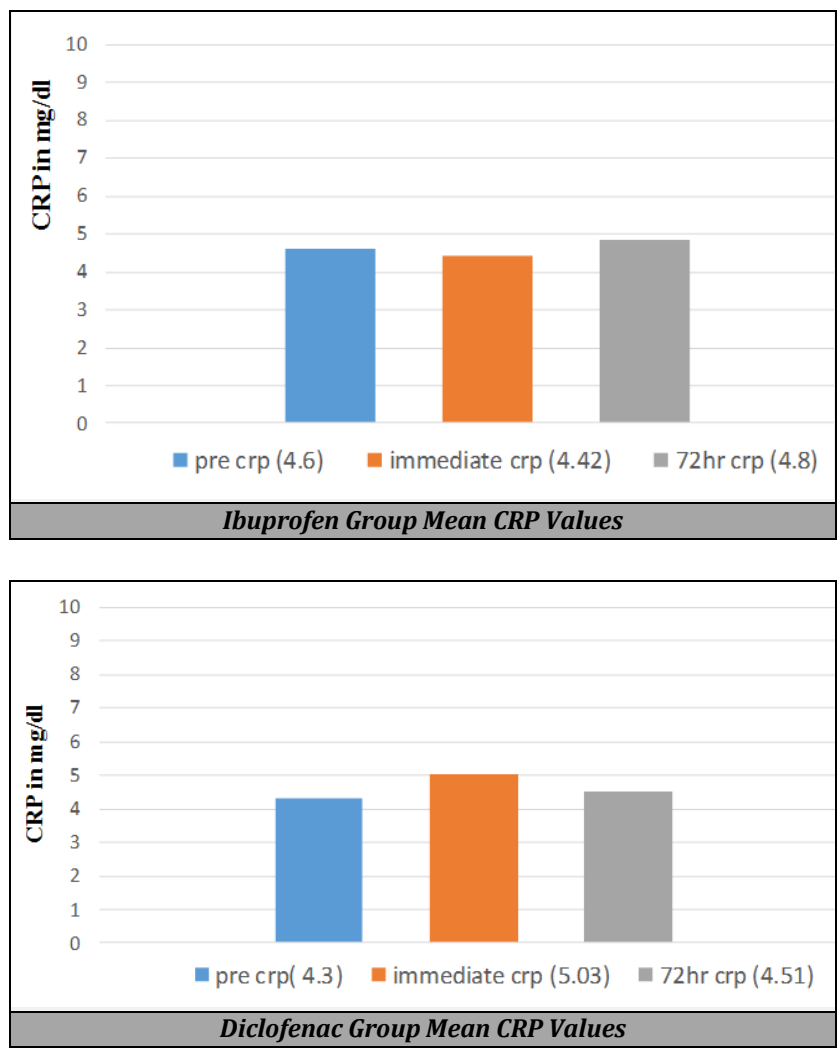

\section{DISCUSSION}

Approximately $96 \%$ of the Indian population suffers from third molars impactions. ${ }^{9}$ The lower third -molar surgery is a typical model for estimating the analgesic \& antiinflammatory drugs effects ${ }^{10}$ as the procedure is often linked with hard and soft tissue manipulation leading to activation of the acute-phase inflammatory response which progresses with some common postoperative sequelae, pain, swelling, trismus, and the cytokines playing the major role.

The NSAIDs have been familiarized in dentistry for controlling the postoperative sequelae. ${ }^{9}$ In this list of NSAIDs, non-selective COX inhibitors have effective analgesic, antiinflammatory action and also in decreasing the cytokines levels and acute phase response via reducing the PGE2 (prostaglandin) released in the extracted socket.11

Oral and maxillofacial surgery is well known and trained for over 200 years. There are a variety of disease processes and surgical techniques involved in this profession. All these conditions lead to the development of acute-phase responses.
This response and release of CRP enable surgeons to administer anti-inflammatory drugs, corticosteroids and antibiotic therapy thus helping in monitoring the duration of use.

Chander et al. investigated the preoperative and postoperative CRP levels and postoperative pain and swelling in 102 patients undergoing third molar surgery. In this the venous blood was withdrawn at 24 hours, 48 hours and 7 days using a latex slide agglutination method to assess the CRP levels and preoperative pain and swelling were also assessed using a verbal analogue scale, thread length measurement, and mouth opening. The results showed that pain control CRP levels postoperatively were raised in those cases which had high preoperative levels with a significance of $(\mathrm{P}<.005)$ and at 48 hours postoperatively with a significance of $(\mathrm{P}>0.025)$. CRP level in blood readings in postoperative swelling showed $(\mathrm{P}<0.4$ to 0.1$)$ and concluded that C-reactive protein was a trustworthy indicator than other indicators like preoperative swelling and inflammation measurements for prediction of postoperative symptoms of third molar surgery.

Gaurav Salgia et al. ${ }^{8}$ conducted a study to evaluate the efficacy of CRP and three NSAIDs in postoperative inflammation and pain control in 60 patients. CRP was evaluated preoperatively and postoperatively after surgical extraction of third molars using the latex agglutination method. The respective group received the drugs by random coding postoperatively. The parameters were to assess the pain control and inflammation postoperatively by analyzing CRP levels qualitatively and quantitatively at immediate and $72 \mathrm{hr}$ postoperatively. The visual analogue scale was used for assessing the pain and its relationship with CRP levels. There was a significant increase in CRP levels in immediate postoperative values and at $72 \mathrm{~h}$. They proved CRP estimation to be a useful tool for monitoring post-surgical inflammation and pain using NSAIDs.

Graziani et al.12 conducted the case-control study, they evaluated the host response with or without a lower third molar and the effects of their surgical removal on biomarkers of systemic inflammation and endothelial function. A total of 40 patients were grouped as control group and tooth removal group. The results showed that a rise in the serum levels of $\mathrm{C}$ -reactive protein and fibrinogen were noticed in the first postoperative week and $3^{\text {rd }}$ month after the extraction.

In our study, symptomatic impacted third molars were chosen for surgical removal that was carried out in twenty healthy volunteering young adults. We used a serum CRP as a biomarker to analyze the pain control and the antiinflammatory effects of diclofenac \& ibuprofen drugs during preoperative, $1 \mathrm{hr}$ immediate postoperative and $72 \mathrm{hr}$ postoperative phases. In the surgical cases of the diclofenac group, the analgesic effect showed a VAS $3^{\text {rd }}$ day mean value of (3.6) score, the VAS $4^{\text {th }}$ day showed a mean value (3.1) and VAS $5^{\text {th }}$ day had a mean value of (1.8) score. The antiinflammatory effect of diclofenac groups had a pre-op CRP level of $(4.3 \mathrm{mg} / \mathrm{dl})$ and $72 \mathrm{hr}$ post-op CRP levels of (4.51 $\mathrm{mg} / \mathrm{dl})$. Whereas the surgical cases of the ibuprofen group, showed VAS $3^{\text {rd }}$ day mean value of (8.6) score, the VAS $4^{\text {th }}$ day mean value (7.9) score and VAS $5^{\text {th }}$ day mean value of (7.1) score. The anti-inflammatory effect of ibuprofen group had pre-op CRP level of ( $4.6 \mathrm{mg} / \mathrm{dl}) \& 72 \mathrm{hr}$ post-op CRP 
levels of $(4.8 \mathrm{mg} / \mathrm{dl})$. Thus this study established that the diclofenac drug has a better effect in controlling pain and inflammation than the ibuprofen group.

\section{Limitation}

The authors are well aware of the limitations of the study. Firstly, despite the formal sample size used for estimation, still, a large sample size is required for the descriptive analysis. Secondly, longer follow-ups are required to assess the return of their actual pre-surgical values after the cessation of the stimulus. Thirdly there is a need for the verification of the drug raw material.

\section{CONCLUSIONS}

The motive of this study was to analyze the drug-induced effects on pain and inflammation post-surgically in patients undergoing third molar surgeries with the help of a potent biomarker like C-reactive protein. Firstly, we established that a drug like diclofenac had a better analgesic and antiinflammatory effect than ibuprofen based on the C Reactive Protein values. Secondly, the uniqueness of the rising and falling of the serum CRP concentration and its usefulness in monitoring the pre-surgical activity and also its effects during the postsurgical period. Apart from this in our observation, we were able to determine that the gender, age, difficulty index and duration of surgery had a minimal role in affecting the serum CRP concentration and found it to be stable.

\section{REFERENCES}

[1] Cole DS, Watts A, Scott-Coombes D, et al. Clinical utility of perioperative $\mathrm{C}$-reactive protein testing in general surgery. Ann R Coll Surg Engl 2008;90(4):317-21.
[2] Cray C, Zaias J, Altman NH. Acute phase response in animals: a review. Comp Med 2009;59(6):517-26.

[3] Chander PM, Ali FM, Aher V. C-reactive protein a better indicator of inflammation after third molar extraction. Niger J Clin Pract 2013;16(3):297-301.

[4] Chandra P, Suman P, Airon H, et al. Prospects and advancements in C-reactive protein detection. World J Methodol 2014;4(1):1-5.

[5] Du Clos TW. Pentraxins: structure, function, and role in inflammation. ISRN Inflamm 2013;2013:379040.

[6] Das T, Sen A, Kempf T, et al. Induction of glycosylation in human $\mathrm{C}$-reactive protein under different pathological conditions. Biochem J 2003;373(Pt 2):345-55.

[7] Esteller-Martínez V, Paredes-García J, ValmasedaCastellón E, et al. Analgesic efficacy of diclofenac sodium versus ibuprofen following surgical extraction of impacted lower third molars. Med Oral Patol Oral Cir Bucal 2004;9(5):444-53.

[8] Salgia G, Kulkarni DG, Shetty L. C-reactive protein estimation: a quantitative analysis for three nonsteroidal anti-inflammatory drugs: a randomized control trial. Indian J Dent Res 2015;26(1):43-7.

[9] Sivaramakrishnan SM, Ramani P. Study on the prevalence of eruption status of third molars in South Indian Population. Biol Med (Aligarh) 2015;7:245.

[10] Franco-Molina MA, Mendoza-Gamboa E, CoronadoCerda EE, et al. Clinical trial evaluating the effectiveness of bio-compound immunepotent -CRP in the third-molar extraction. Biotechnology \& Biotechnological Equipment 2017;31(1):182-6.

[11] Mehra P, Reebye U, Nadershah M, et al. Efficacy of antiinflammatory drugs in third molar surgery: a randomized clinical trial. Int J Oral Maxillofac Surg 2013;42(7):835-42.

[12] Graziani F, Aiuto FD, Gennai S, et al. Systemic inflammation after third molar removal:a case-control study. J Dent Res 2017;96(13):1505-12. 